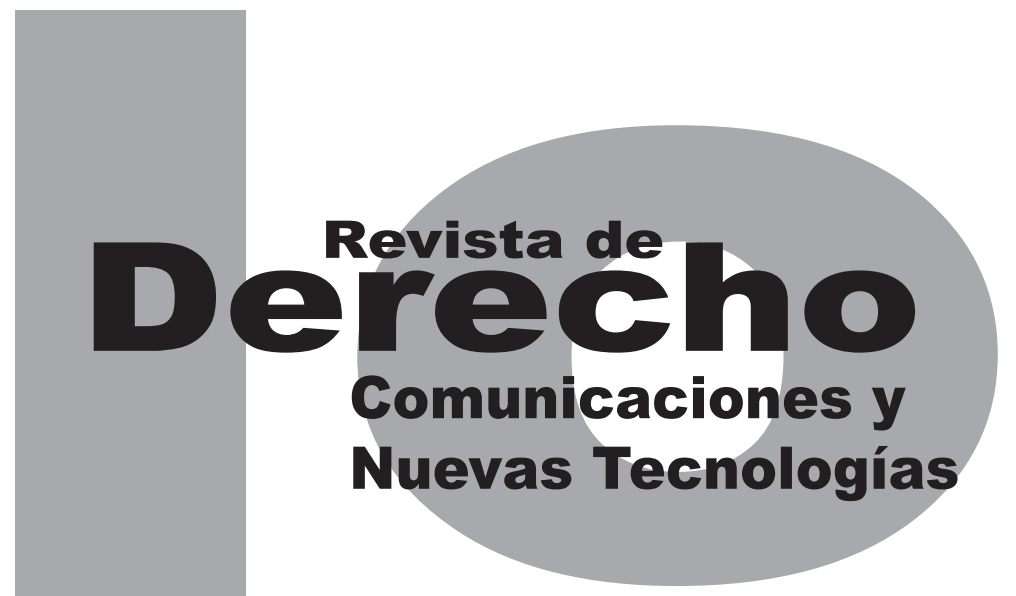

\title{
Sistemas de navegación sateltTal. DesarRollo, REGLAMENTACIÓN JURÍDICA Y TRASCENDENCIA EN EL MUNDO CONTEMPORÁNEO
}

\author{
Carolina lópez \\ JuAn PABlo De GuzMÁN \\ Artículo de investigación científica y tecnológica \\ DOI: http://dx.doi.org/10.15425/redecom.12.2014.09 \\ Universidad de los Andes \\ Facultad de Derecho
}

Revista de Derecho, Comunicaciones y Nuevas Tecnologías

No. 12, Julio - Diciembre de 2014. ISSN 1909-7786 


\section{Sistemas de navegación satelital. Desarrollo, reglamentación jurídica y trascendencia en el mundo contemporáneo}

\section{Resumen}

Desde el inicio de la humanidad, el hombre ha tenido la necesidad de determinar su posición en la Tierra. Esta es la razón detrás del surgimiento de los sistemas de navegación en tiempos tan remotos como la era vikinga, griega y romana, con sistemas precarios que dependían exclusivamente de los fenómenos físicos de la Tierra, tales como el sol, la Luna y las estrellas. Como tal, estos sistemas se desactualizaban constantemente, precisamente por el cambio en los fenómenos físicos de la Tierra.

El descubrimiento del espacio exterior y su posterior conquista fueron los primeros pasos hacia un adelanto en la historia, pues estos logros dieron paso a una nueva era en la navegación al proporcionar a la humanidad un sistema basado en la triangulación de las señales satelitales, que fuera completamente independiente de los elementos físicos en la Tierra, convirtiendo este sistema en uno más confiable y preciso.

Palabras Clave: sistemas de navegación satelital, GPS, norma espacial, derecho del espacio ultraterrestre, corpus iuris spatialis.

\section{Satellite navigation systems. Development, ruling and relevance in the contemporary world}

\section{Abstract}

From immemorial time human beings have felt the need to determine their location on earth. This is the reason for navigation systems emerging as early as the Viking, Greek and Roman eras. Those very precarious systems relied exclusively on the physical elements on earth, such as the sun, the moon and the stars and therefore became outdated as those physical characteristics on earth kept shifting. The discovery of outer space and, later, the first manned landing on the moon, were indeed a step forward in history. These achievements gave way to a new age in navigation by providing humankind with a system based on the triangulation of satellite signals, completely independent from the physical elements on earth. Consequently, the system became much more reliable and precise.

In today's world satellite navigation has evolved dramatically and, yet, there are no clear legal rules on the matter in the framework of the corpus iuris spatialis. Thus, at this point in time, an analysis of the current legal framework seems appropriate. The present document intends identifying, on the basis of the suggested analysis, some new rules to govern the activities of satellite navigation, the effectiveness of current space law and issues relating to privatisation, responsibility for damage and registration of navigation satellites in light of the principle of sovereignty.

Key words: satellite navigation systems, GPS, spatial legal norm, space law, corpus iuris spatialis.

\section{Sistemas de navegação por satélite. Desenvolvimento, regulamentação jurídica e transcendência no mundo contemporâneo}

\section{Resumo}

Desde o início da humanidade, o homem tem sentido a necessidade de determinar sua posição na terra. Esta é a razão detrás do surgimento dos sistemas de navegação em tempos tão remotos como a era viking, grega e romana, com sistemas precários que dependiam exclusivamente dos fenômenos físicos da terra, tais como o sol, a lua e as estrelas. Como tal, estes sistemas se desatualizavam constantemente precisamente pela mudança nos fenômenos físicos da terra. O descobrimento do espaço exterior e sua posterior conquista foram os primeiros passos para um progresso na história, pois estas conquistas deram passo a uma nova era na navegação ao proporcionar à humanidade um sistema baseado na triangulação dos sinais de satélites, que fosse completamente independente dos elementos físicos na terra, transformando este sistema em um mais confiável e preciso.

Palavras-chave: sistemas de navegação por satélite, GPS, norma espacial, direito do espaço ultraterrestre, corpus iuris spatialis. 


\title{
Sistemas de navegación satelital. Desarrollo, reglamentación jurídica y trascendencia en el mundo contemporáneo*
}

\author{
Carolina López \\ Juan Pablo De Guzmán**
}

\section{SUMARIO}

I. INTRODUCCION Y ORÍGENES DE LA NAVEGACIÓN - II. DERECHO Y ESPACIO - A. ¿Qué es el espacio ultraterrestre? - B. Conceptos básicos sobre el espacio ultraterrestre - III. LOS OBJETOS ESPACIALES Y LAS ÓRBITAS - A. ¿Qué son los objetos espaciales? - B. ¿Qué son las órbitas? - IV. SATÉLITES - A. ¿Qué son los satélites? - B. Tipos de satélites - C. Importancia de los satélites y los sistemas de navegación satelital - V. SISTEMAS DE NAVEGACIÓN SATELITAL - A. Historia - B. Características técnicas - 1. Segmento Espacial - 2. Segmento de control - 3. Segmento de usuario - A. Funcionamiento - B. Aplicaciones - 1. Usos civiles - 2. Usos militares - VI. REGLAMENTACIÓN JURÍDICA DE LOS SISTEMAS DE NAVEGACIÓN SATELITAL - A. Fuerza vinculante de la norma jurídica - B. Propiedad, registro y privatización - C. Soberanía - D. Responsabilidad por la información que obtiene el satélite - VII. CONCLUSIONES - Referencias

\footnotetext{
* Cómo citar este artículo: López, C. y De Guzmán, J. P. (Diciembre, 2014). Sistemas de navegación satelital. Desarrollo, reglamentación jurídica y trascendencia en el mundo contemporáneo. Revista de Derecho, Comunicaciones y Nuevas Tecnologías, 12. Universidad de los Andes (Colombia).

** Estudiantes de noveno semestre de Derecho de la Universidad de los Andes.
} 


\section{INTRODUCCIÓN Y ORÍGENES DE LA NAVEGACIÓN}

Polaris, Kynosaura, Cynosaura o Ursae Minoris son solo algunos de los nombres para la estrella polar, una estrella ubicada a pocos grados del polo norte celeste, razón por la cual permanece fija sobre la bóveda celeste, convirtiéndola en el mejor referente para determinar la latitud en la navegación.

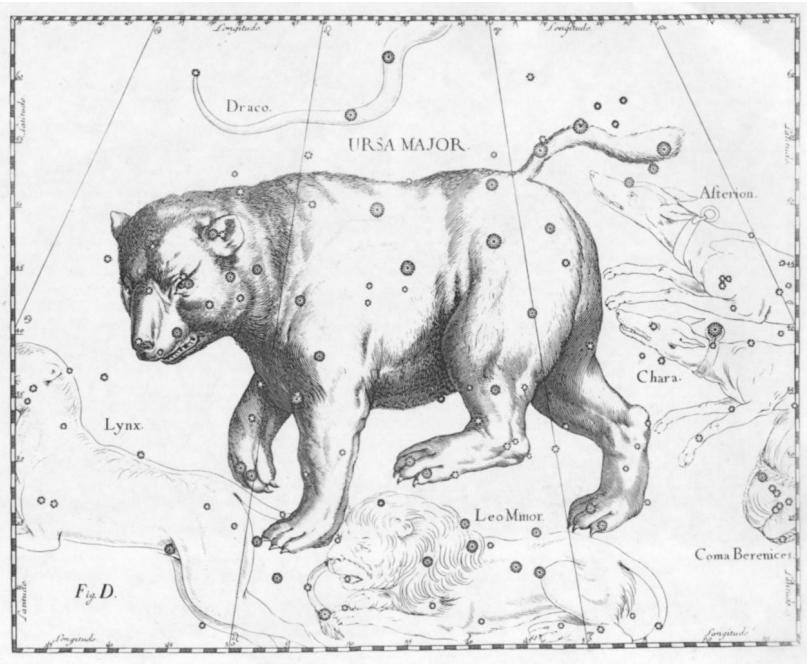

Fuente: Canes Venatici constellation, de Uranographia, Johannes Hevelius.

De origen mítico, cuentan los griegos que Calisto, cazadora del cortejo de Artemisa, fue seducida por Zeus y como fruto de esta seducción, nació Arcos. A razón de esto, Hera, esposa de Zeus, decidió convertir a Calisto en osa y encomendó a Artemisa su caza. Zeus, por su parte, en un intento por protegerla a ella y a su hijo, los convirtió a ambos en constelaciones para otorgarles la inmortalidad y protegerles de los celos de Hera. Entonces, las nuevas constelaciones -Calisto convertida en la Ursae Majoris junto con su hijo Arcos convertido en Ursae Minoris-, fueron ubicados cerca del polo, con la intención de que nunca cruzaran la línea del horizonte, según lo dispuesto por Tetis, madrina de Hera, en un ataque de celos tras la incursión de Calisto en el lecho de su ahijada (Bell).

El anterior mito es solo un reflejo de necesidad del hombre por explicar el origen de la estrella polar, el mejor referente para obtener la ubicación exacta en la Tierra, un interés constante desde el momento mismo en que el hombre decidió desplazarse. Así, la invención de sistemas de navegación y la designación de puntos de referencia en el cielo, como Polaris, se convirtieron en los mejores aliados en el transporte de los seres humanos. Sin embargo, por ejemplo, para los navegantes vikingos del Atlántico Norte, la falta de una noche oscura en el verano, época propicia para la navegación, presentaba un obstáculo para la astronavegación, por lo que, según relatan las Sagas islandesas, documentos que relatan los siete trayectos navegados por los vikingos, recurrieron a la creación de unos discos de madera en los que demarcaban la sombra generada por equinoccios y solsticios de verano, de manera tal que, a falta de noche, pudieran usar la sombra del Sol para comparar su posición respecto de las marcas (Thirslund, 2007).

El anterior sistema, junto con el posterior invento de las cartas de navegación (también relatadas en las Sagas islandesas), y la invención de la brújula, fueron desarrollos primitivos de lo que hoy se conoce como el Sistema de Navegación Satelital, basado en el uso de satélites ubicados en el espacio ultraterrestre. Sin embargo, para 
poder entender su funcionamiento es menester explicar qué es el espacio ultraterrestre, cuáles son los principios por los que se rige su uso y qué reglamentación existe y es aplicable a los sistemas de navegación satelital.

\section{DERECHO Y ESPACIO}

\section{A. ¿Qué es el espacio ultratarrestre?}

El espacio ultraterrestre es "un vacío, un lugar donde no hay absolutamente nada, en donde no se pueden transmitir ondas mecánicas (como el sonido) sino solamente ondas electromagnéticas (como la luz y las ondas de radio). Dentro del espacio se encuentran diferentes tipos de objetos tales como: planetas, estrellas, asteroides, cometas, nebulosas, galaxias y hoyos negros" (Contreras, 2013). De esta manera, la combinación de todos los elementos anteriormente descritos es lo que se conoce como universo y se ha planteado teóricamente que el mismo es infinito, por lo que no cuenta con un límite superior. Sin embargo, frente a su límite inferior, se ha planteado la distancia de 100 kilómetros sobre el nivel del mar como el punto a partir del cual se acaba el espacio aéreo sobre el que los Estados tienen soberanía y comienza el espacio ultraterrestre.

Como se mencionó anteriormente, el espacio es vacío, no hay materia y por lo tanto ocurren una serie de fenómenos particulares, como el hecho de que los objetos que allí se encuentren no navegan, pues no tienen un medio para hacerlo, sino que simplemente se desplazan al impulsar materia en la dirección opuesta a la que el objeto se dirige (Contreras, 2013).

\section{B. Conceptos básicos sobre el espacio ultraterrestre}

Es natural que algo tan particular como el espacio ultraterrestre no pudiera ser regulado por los tratados tradicionales de derecho internacional público, sino por un cuerpo normativo único denominado corpus iuris spatialis. Por esta razón y debido a la coyuntura que vivía la humanidad hacia finales de la Segunda Guerra Mundial, la amenaza que representaba la conquista del espacio ultraterrestre con fines bélicos se hizo más evidente con la puesta en órbita del Sputnik 1 de la Unión Soviética el 4 de octubre de 1957, iniciando la denominada carrera espacial entre la Unión Soviética y los Estados Unidos.

El resultado de dicha carrera, más allá de cuál Estado fue vencedor, sin lugar a dudas fue el beneficio de la humanidad entera, pues dicha carrera solo acrecentó el interés por el espacio ultraterrestre y llevó, entre otros, a que Estados Unidos inaugurara la Agencia Nacional de Aeronáutica y del Espacio (NASA, por su siglas en inglés) para desarrollar misiones al espacio y aumentar el conocimiento de este. Asimismo, el impacto de la puesta en órbita de un objeto espacial junto con el miedo que este generó, impulsó a la Asamblea General de las Naciones Unidas a crear en 1958 el Comité ad hoc de Uso Pacífico del Espacio Ultraterrestre (Copuos, por sus siglas en inglés) a través de la Resolución 1358. Asimismo, la XVIII Sesión de la Asamblea General de las Naciones Unidas aprobó en 
1963 dos resoluciones acerca de los principios jurídicos que debían regir el espacio y la prohibición general del uso de armas en este.

Ya en el año 1967, con la aprobación de la Resolución 2222 de la Asamblea General de las Naciones Unidas, se ratificó el Tratado sobre los principios que debían regir las actividades de los Estados en la exploración y utilización del espacio ultraterrestre, incluso la Luna y otros cuerpos celestes, conocido también como la Constitución del Espacio, en la cual finalmente se plasmaron los principios que se venían desarrollando desde la Carta de las Naciones Unidas y las Resoluciones de 1962 y 1883.

Los principios establecidos son: (i) la no apropiación del espacio, (ii) el uso pacífico, (iii) la cooperación internacional y (iv) la libertad de acceso y de investigación científica. El primer principio responde a que no hay soberanía en el espacio ultraterrestre y al hecho de que este es res communis de la humanidad. El segundo responde al principio fundamental cuando se creó la Organización de las Naciones Unidas de evitar el flagelo de la guerra. Además, responde a la preocupación de los Estados de que el espacio se convirtiera en un nuevo campo de batalla. Finalmente, el principio de cooperación internacional se refiere a la colaboración que debe existir entre los Estados para el uso del espacio, de manera tal que este se convierta en el escenario para estrechar los lazos existentes entre los mismos (Sussmann, 2013).

Todo lo anterior, además de estar cimentado en el principio de confianza, trae como consecuen- cia el que todos los Estados parte tengan la certeza de que no habrá un nuevo conflicto internacional, al menos en el espacio ultraterrestre, y que de existir diferencias con otros Estados, estas serán resueltas por medio de los mecanismos creados en los tratados. Por esta razón es que este derecho se conoce como el derecho de la paz.

Como consecuencia de la confianza mencionada anteriormente, y en lo que tiene que ver con el ámbito de aplicación del derecho espacial, este es aplicable a todos los Estados parte de los diferentes tratados por todas las actividades que involucren un objeto espacial, según su definición en el Convenio sobre el Registro de Objetos Lanzados al Espacio Ultraterrestre, aprobado por la Asamblea General en su Resolución 3235 del 12 de noviembre de 1974.

\section{LOS OBJETOS ESPACIALES Y LAS ÓRBITAS}

\section{A. ¿Qué son los objetos espaciales?}

\section{Entonces,}

los objetos espaciales son bienes muebles registrables que tienen como finalidad llegar al espacio ultraterrestre. Son registrados como propiedad de uno de los Estados de lanzamiento (esto es el Estado que lanza el objeto, que promueve el lanzamiento o desde cuyo territorio o instalaciones se lance el objeto) y su registro implica la obligación de llevar un registro nacional por parte del Estado propietario, y uno internacional que es aquel que lleva el secretario general de la ONU. (Botero, 2013) 
Una vez que llegan al espacio, estos objetos recorren una trayectoria con relación a otro objeto por la acción de las fuerzas naturales de gravitación. Dicho en términos más simples, estos objetos, una vez en el espacio ultraterrestre, orbitan o generan órbitas.

\section{B. ¿Qué son las órbitas?}

Las órbitas, como se explicó anteriormente, son "la trayectoria que describe, con relación a un sistema de referencia especificado, el centro de gravedad de un satélite o de otro objeto espacial, por la acción única de fuerzas naturales, fundamentalmente por la de gravitación" (Gómez, 2012).

Las órbitas, a su vez, se clasifican según el cuerpo que orbitan, su forma, uso e inclinación. Para propósitos de este documento se va a hablar de las órbitas terrestres, específicamente de las órbitas medias, conocidas como las Medium Earth Orbits (MEO, por sus siglas en inglés). Es decir, aquellas que se encuentran entre los 10075 y los $20150 \mathrm{~km}$. Esta distancia entre la órbita y la superficie de la Tierra determina la velocidad a la cual los satélites se van a mover. Por esta razón, un satélite ubicado a esta distancia se demorará un promedio de doce horas para dar una órbita completa a la Tierra (NASA, 2014).

\section{SATÉLITES}

Como se mencionó anteriormente, las órbitas no existen per se, sino que son la trayectoria creada por un objeto espacial respecto de otro.
Entonces, los objetos espaciales que crean la órbita imaginaria MEO alrededor de la Tierra son satélites. Específicamente, son satélites de navegación satelital.

\section{A. ¿Qué son los satélites?}

Como primera medida, los satélites son lunas, planetas o máquinas que orbitan un planeta o estrella. Pueden ser naturales o artificiales dependiendo de si existen en el universo o si son creados por el hombre, y están compuestos esencialmente por una antena y una carga útil. La antena le permite recibir y enviar información, mientras que la carga útil le proporciona energía. Algunos satélites tienen como carga útil la hidracina, que es un combustible, mientras que otros cuentan con paneles solares como fuente energética.

\section{B. Tipos de satélites}

Dependiendo de la actividad que realizan, los satélites pueden ser de diferentes tipos. En lo que concierne a este documento, se hablará de los satélites de posicionamiento global que se encuentran en las órbitas MEO de la Tierra.

\section{Importancia de los satélites y los sistemas de navegación satelital}

Ahora bien, si se tiene en cuenta la función de los sistemas de navegación satelital, que es la de determinar la localización de una persona u objeto en la tierra a partir del uso de un satélite de posicionamiento global, el primer aspecto que sale a relucir es que el uso de satélites 
proporciona una solución a los diferentes obstáculos que tenían otros sistemas de navegación, como la falta de noche o la presencia de nubes, en el caso de la astronavegación, como se mencionó anteriormente. De igual forma, por las aplicaciones militares y civiles que serán expuestas a continuación, se puede afirmar que estos satélites son de vital importancia para el desarrollo de la ciencia y tecnología.

\section{SISTEMAS DE NAVEGACION SATELITAL}

Profundizando en lo anterior, un sistema de navegación satelital es aquel que permite establecer la posición global de un objeto que se encuentra en la superficie terrestre (Robertson, 2014). Con el fin de entender cómo funciona este importante sistema de geolocalización que revolucionó el mundo en el último siglo, es necesario, en primer lugar, entender a fondo un concepto relacionado con la materia.

Para el efecto, dicho concepto es el de coordenadas terrestres. Es necesario entender plenamente este concepto, precisamente porque mediante la identificación de las coordenadas geográficas es posible localizar un objeto en un punto particular del globo terrestre. Así, el sistema de coordenadas geográficas es aquel que utiliza dos coordenadas angulares, es decir la latitud (Norte y Sur) y longitud (Este y Oeste), para identificar un objeto en la Tierra. La latitud hace referencia al ángulo existente entre un punto en cualquier lugar de la Tierra y el Ecuador. En cambio, la longitud es el ángulo en grados que indica la posición este-oeste de un punto sobre la superficie terrestre a partir del meridiano de Greenwich (Mathematics Dictionary, 2014). Así pues, cuando se combinan estos dos ángulos, es posible identificar claramente la posición de un objeto en la Tierra.

Ahora bien, teniendo claro este concepto, se analizará la historia y surgimiento de los sistemas de navegación satelital, para posteriormente analizar tanto sus características técnicas como su funcionamiento, y terminar con las aplicaciones o usos que se les ha dado en la actualidad.

\section{A. Historia}

La historia del sistema de navegación satelital en el mundo puede remontarse a 1960, cuando el mismo fue concebido y desarrollado por la Fuerza Aérea de los Estados Unidos de América, con el propósito inicial de localizar barcos y submarinos enemigos. Posteriormente, hacia 1974, ante la efectividad del mismo en el campo aéreo, se fue introduciendo el sistema en todas las demás divisiones de las fuerzas militares americanas. Ante la utilidad práctica que se pudo ver en el campo militar, los norteamericanos decidieron lanzar los primeros satélites a partir de 1978, con el fin de construir un sistema que les permitiera tener una ventaja competitiva sobre los demás países (Robertson, 2014). Así pues, a partir del año de 1989 y hasta el año de 1997, alrededor de 24 satélites fueron lanzados por los Estados Unidos, con el fin de crear una gran constelación de objetos artificiales. 
Ahora bien, con el paso de los años, los Estados Unidos tomaron la decisión de desclasificar el sistema, dando el primer paso real para el surgimiento del conocido mundialmente Sistema de Posicionamiento Global, comúnmente conocido por sus siglas en inglés como GPS. De esta manera, el sistema de navegación satelital pasó de ser un sistema exclusivamente con fines bélicos, a ser un sistema para el beneficio de toda la humanidad.

Al día de hoy, el sistema norteamericano GPS es el más completo de todos los sistemas de navegación satelital en el mundo. Sin embargo, este no es el único sistema de navegación satelital que existe en la actualidad en el planeta Tierra. Otras potencias mundiales, tales como los países que conforman la Unión Europea, decidieron construir su propia constelación de satélites de navegación, con el fin de reducir la dependencia del sistema norteamericano. Así, se espera, por ejemplo, que para el año 2014 el sistema Galileo entre en operación y permita prestar el mismo servicio de navegación por satélite que presta el sistema GPS de los estadounidenses. De la misma manera, es pertinente mencionar el sistema de navegación satelital de Rusia, denominado Glonass y el de China denominado Compass.

\section{B. Características técnicas}

Para el efecto, con el fin de entender algunas de las características técnicas de un sistema de navegación por satélite, tomaremos el ejemplo del sistema más desarrollado, el Sistema de Posicionamiento Global (GPS - NAVSTAR) de los
Estados Unidos. Sin embargo, vale la pena aclarar que sistemas como el Galileo o el Glonass funcionan de forma muy similar y prácticamente tienen los mismos componentes.

Siendo esto así, en lo que se refiere a las características técnicas del Sistema de Posicionamiento Global norteamericano de los Estados Unidos, es necesario mencionar que el mismo se compone de tres grandes segmentos. Así pues, analizaremos cada uno de dichos segmentos, con el fin de entender cómo es que realmente funciona todo este complejo sistema de satélites que envían señales alrededor de la Tierra, con el fin de identificar las coordenadas exactas en las cuales se encuentra ubicado un objeto.

\section{Segmento espacial}

El primero de los segmentos que componen el Sistema de Posicionamiento Global norteamericano tiene el nombre de segmento espacial. Dicho segmento consiste de satélites que giran alrededor de la Tierra, aproximadamente a 17700 kilómetros. Lo anterior quiere decir que estos satélites orbitan en órbitas medias, considerando que las órbitas medias están ubicadas aproximadamente entre los 10000 y 20000 kilómetros del globo terrestre. Ahora bien, en este segmento los satélites se ubican en puntos específicos del espacio, con el fin de que circulen por una órbita y a una velocidad específica. Las funciones principales de los satélites que componen este segmento se pueden resumir en que se encargan de almacenar la totalidad de la información que reciben de las diferentes 
estaciones de control ubicadas en la Tierra, y de enviar la señal a los diferentes receptores que hacen uso del Sistema de Posicionamiento Global, tales como vehículos, celulares y hasta aviones y barcos.

\section{Segmento de control}

Por otro lado, el segundo de los segmentos que componen el Sistema de Posicionamiento Global de los Estados Unidos es el segmento de control. Este segmento permite hacerle un seguimiento constante a cada uno de los satélites, entregándoles constantemente información sobre la órbita que deben seguir. El segmento de control está compuesto por cuatro estaciones automáticas, ubicadas en diferentes puntos geográficos y en una estación central de control de todo el sistema. Las cuatro estaciones automáticas son las estaciones de Hawaii, Ascension Island, Diego García y Kwajalein, y la estación de Colorado Springs es la estación central del sistema (Rizos, 1999). En términos generales, el sistema funciona en la medida en que las cuatro estaciones automáticas reciben la información directamente de los satélites y posteriormente envían la información recolectada a la estación principal, en donde la misma es enviada, con las correcciones necesarias, de vuelta a cada uno de los satélites que componen la constelación artificial.

\section{Segmento de usuario}

Por último, tenemos el segmento de usuario. Como bien lo dice su nombre, este segmento se compone principalmente de los usuarios de la información que envían los satélites, y que permiten cumplir con la función principal de un Sistema de Posicionamiento Global: la identificación de las coordenadas exactas de un objeto en la Tierra.

\section{Funcionamiento}

Ahora bien, teniendo claros los diferentes segmentos que componen el Sistema de Posicionamiento Global norteamericano, y en general un sistema de navegación satelital en el mundo, el siguiente paso es entender cómo funciona realmente dicho sistema, y cómo se logra ubicar el punto preciso en donde se encuentra ubicado un objeto en el planeta Tierra. Para efectos de entender completamente su funcionamiento, utilizaremos el ejemplo de un teléfono celular, el cual a través de una aplicación específica nos permite ver el punto preciso en el planeta Tierra en donde estamos ubicados.

Así pues, el proceso comienza cuando un receptor es encendido en algún punto del planeta Tierra, siendo en este caso un teléfono celular. En ese preciso instante en el que el dispositivo es encendido, el dispositivo descarga inmediatamente la información de todos los satélites que componen la constelación artificial. La primera vez que se realiza este proceso en un dispositivo, el mismo puede tener una duración de algunos minutos, pero una vez se realiza por primera vez, la información satelital se guarda directamente en la memoria del mismo.

Ahora bien, teniendo el dispositivo específico la información orbital de cada uno de los satélites, 
así como la frecuencia a la cual están transmitiendo su información, necesariamente es esencial conocer la distancia precisa que existe entre el dispositivo receptor y cada uno de los satélites que orbitan en el espacio. Esa distancia se calcula multiplicando la velocidad de la señal transmitida por el tiempo que toma la señal en alcanzar cada receptor. Siendo esto así, es necesario mencionar que una de las dos variables que hacen parte de la fórmula que utiliza el receptor para calcular la distancia que tiene con el satélite es una variable fija. Esta variable fija es la velocidad de la señal transmitida, considerando que las ondas que transmiten los satélites son ondas radio, las cuales se transportan a la velocidad de la luz (300 000 kilómetros por segundo). Por lo tanto, es necesario simplemente calcular el tiempo que se demora dicha onda a la velocidad de la luz, en alcanzar el receptor en la Tierra. Para efectos de determinar el tiempo, el receptor automáticamente iguala el código del satélite con su propio código, con el fin de compararlos y determinar de esta manera qué tanto debe adaptar su propio código para igualar el código del satélite. Este tiempo de retraso será el tiempo que utilizará el receptor para posteriormente multiplicarlo por la velocidad de la onda (la velocidad de la luz) y obtener la distancia que tiene con el satélite (Georgia State University, 2008).

Teniendo clara la distancia entre el receptor y un satélite específico, el receptor debe ahora repetir el proceso de identificación de la distancia con al menos otros dos satélites, para recibir finalmente un total de tres señales diferentes. Así pues, con la información recibida de estas tres señales, el receptor logrará identificar la posición exacta en donde se encuentra en el planeta Tierra, a través de un proceso de triangulación.

El mejor método para entender el proceso de triangulación es a través de un ejemplo práctico, mediante el cual un receptor mide su distancia con tres satélites diferentes para obtener finalmente las coordenadas geográficas exactas en las que se encuentra ubicado en el planeta Tierra. Así pues, supongamos que el receptor calcula que su distancia con el primer satélite es de 18000 kilómetros. Teniendo esta información, sabemos que el receptor estará en algún punto de una esfera cuyo centro es este primer satélite y cuyo radio es de 18000 kilómetros, tal y como se puede ver en el siguiente diagrama:

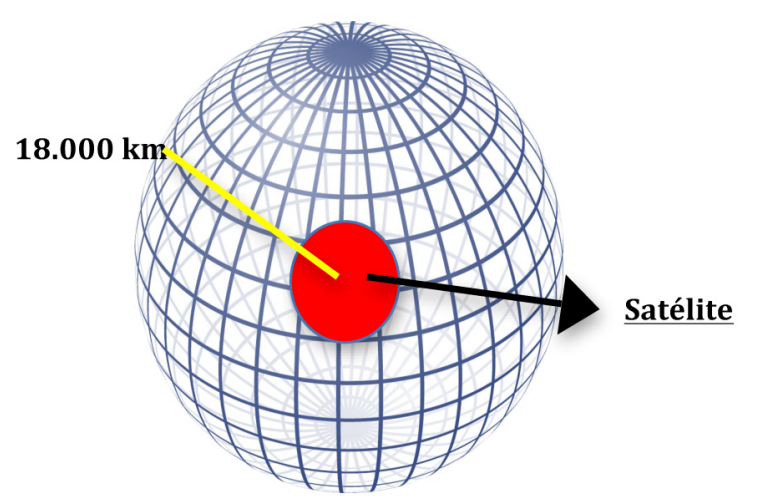

Sabiendo esto, el receptor hará contacto con otro de los satélites y encontrará que este segundo satélite está a una distancia de 19000 kilómetros. Esto, en términos generales, nos dice que estamos dentro de una esfera cuyo centro es el segundo satélite y cuyo radio es de 19000 kilómetros. Pero también nos dice que el receptor estará ubicado en algún punto entre la intersección de las dos esferas, tal y como lo podemos ver reflejado en el siguiente diagrama: 
$18.000 \mathrm{~km}$

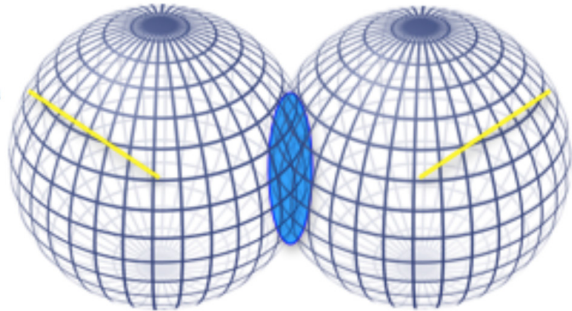

Ahora bien, si tenemos en cuenta la distancia del receptor con un tercer satélite, y encontramos que dicha distancia es de 20000 kilómetros, la posición del receptor en el planeta Tierra se limitaría aún más. Esto limita las posibilidades reales en donde se encuentra el receptor a dos puntos específicos, que serán los dos únicos puntos en los que las tres esferas imaginarias se interceptarían. Para decidir cuál de los dos puntos es el correcto, podría incluirse un nuevo satélite en el ejercicio, pero normalmente es fácil identificar el punto correcto, considerando que lo más común es que uno de los puntos puede ser descartado al estar muy lejos de la superficie terrestre. El siguiente diagrama busca explicar la triangulación que se hace con las distintas distancias en las que se encuentran los satélites, para calcular la longitud y latitud del receptor al que le están siendo enviadas las señales.

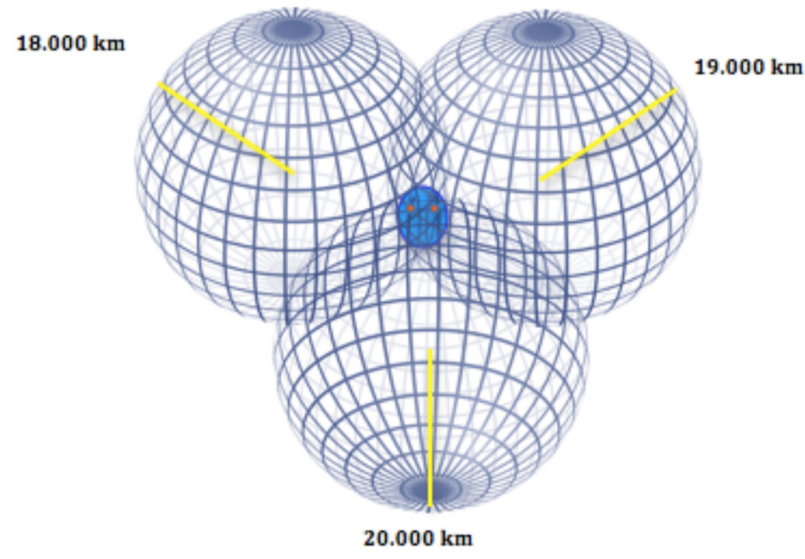

\section{B. Aplicaciones}

Teniendo claro el funcionamiento de un sistema de navegación satelital a través de la triangulación de señales, resulta pertinente analizar cuáles han sido los usos que el ser humano le ha dado a este importante sistema de geolocalización. En consecuencia, a continuación se hará un análisis sobre los usos, tanto civiles como militares, que la humanidad le ha dado a los sistemas de navegación satelital a través del tiempo.

\section{Usos civiles}

Sin duda, el diseño y la creación de un sistema de navegación satelital en el mundo trajeron como consecuencia un cambio tecnológico significativo, sobre todo beneficiando a muchas áreas de la economía mundial e inclusive particularmente a cada individuo. Así pues, si analizamos algunas de estas áreas en las que se le ha dado un uso al sistema, podemos encontrar que la humanidad le ha dado uso al sistema principalmente para la localización de objetos en la superficie terrestre. Al respecto, puede decirse que el sistema de navegación satelital ha sido utilizado para la navegación (entre un punto y otro), para la creación de mapas terrestres y para el monitoreo de objetos, bien sea en el mar, en el espacio aéreo o en la superficie del planeta Tierra.

Ahora bien, en la actualidad podemos encontrar que los sistemas de navegación satelital son usados en la mayoría de automóviles, facilitando los viajes y la ubicación de puntos precisos 
en los diferentes países del mundo. Hoy, los ma2. Usos militares pas de papel han sido reemplazados por sistemas inteligentes que logran identificar las coordenadas exactas en donde se ubica el vehículo y lograr señalar el camino más preciso para llegar a un punto específico en el mapa. Inclusive, hoy en día, los sistemas han alcanzado tal nivel de tecnología que le avisan al usuario sobre el estado del tráfico y le sugieren rutas alternativas, conectándose con los dispositivos de otros vehículos.

Adicional al uso en vehículos automotores, encontramos que el sistema de navegación satelital también es usado, por ejemplo, en el campo marítimo. El uso de este sistema ha permitido, por ejemplo, aumentar la velocidad de los envíos en el transporte de cargo. Así pues, las compañías navieras pueden, a través del sistema de navegación satelital, hacerle un estricto seguimiento a los barcos de carga, hacer un control significativo de la mercancía e inclusive planear rutas alternativas que aumenten la eficiencia del transporte. De la misma manera, en el campo marítimo, el sistema se ha usado para identificar los mejores puntos de pesca en el mar y aumentar la productividad de los pescadores (Chao-Hsu Yao, 2002).

En términos generales, el uso del sistema de navegación por satélite no tiene límites en su aplicación. Los usos son múltiples y el beneficio para los seres humanos, infinito. 


\section{REGLAMENTACIÓN JURÍDICA DE LOS SISTEMAS DE NAVEGACIÓN SATELITAL}

Teniendo claro lo anterior, es pertinente hablar de la reglamentación jurídica de los sistemas en cuestión. Así, a pesar de que no exista un tratado específico sobre los sistemas de navegación satelital, los principios del derecho del espacio al igual que lo que tiene que ver con los diferentes tratados en lo referente a registro y responsabilidad por daños entre otros, son aplicables a los sistemas de navegación satelital.

\section{A. Fuerza vinculante de la norma jurídica}

Para poder entender la reglamentación jurídica de los sistemas de navegación satelital, lo primero que debe abordarse es la fuerza vinculante de la norma jurídica espacial. Así, las normas que se expidieron fueron resoluciones y tratados. De estos, solo son vinculantes los tratados para quienes firmen y las resoluciones no son vinculantes para todos sus miembros, pues son solo resoluciones. Sin embargo, en virtud de la Convención de Viena y en vista de que el derecho espacial se desprende de la Carta de las Naciones Unidas, que es un tratado firmado y ratificado por todos los países, las normas que surjan de dicha asamblea general deberían ser vinculantes (Diago, 2013). ${ }^{2}$

2 De igual manera, en eventos en que el contenido de estas resoluciones derive de la costumbre internacional, estas también serán vinculantes. Ver el artículo 34 de la Convención de Viena sobre la ley de los tratados de 1969.

\section{B. Propiedad, registro y privatización}

Como se mencionó anteriormente, los Estados son los sujetos de derechos y obligaciones frente a la comunidad internacional en lo relacionado con el derecho del espacio ultraterrestre. En lo que tiene que ver con propiedad y registro de los satélites de posicionamiento global, se mantiene lo planteado en el Convenio sobre el registro de objetos lanzados al espacio ultraterrestre, que establece que "se entenderá por Estado de registro un Estado de lanzamiento en cuyo registro se inscriba un objeto espacial"; de igual forma, se tendrá como Estado propietario el Estado de registro del objeto especial.

No obstante, los Estados tienen la potestad de privatizar las actividades estatales, bien sea por el alto costo de realizarlas y por no tener los recursos o simplemente para mejorar el servicio prestado. Sin embargo, el privatizar la actividad espacial no hace que el Estado de registro del objeto espacial (el Estado propietario del objeto) cambie o quede en cabeza del particular, ni exonera de responsabilidad al Estado contratante cuando dicho objeto ocasione daños, como establece el artículo VI del Tratado de 1967 (Naciones Unidas, 2008).

\section{Soberanía}

Ahora bien, la actividad desempeñada por los sistemas de posicionamiento global, bien sea por parte de un Estado parte o de una organización internacional, supone el traspaso de fronteras, pues bien puede ocurrir que el satélite de posicionamiento global de un Estado transmita 
una señal a un dispositivo en el territorio de otro Estado, u obtenga la localización de objetivos militares u otra información sensible cuyo uso inapropiado puede vulnerar los intereses de otro Estado parte.

La respuesta a estos posibles problemas debe surgir desde los principios mismos del derecho del espacio, de cooperación internacional y uso pacífico. Así pues, de forma similar a como ocurre con los sistemas de teleobservación de la Tierra, en los que el Estado que realice actividades de teleobservación de la Tierra debe ofrecer la información obtenida al Estado observado, a un precio justo y razonable, los sistemas de posicionamiento global que traspasen fronteras lo podrán hacer, teniendo en cuenta los principios de cooperación internacional y de uso pacífico. Esto quiere decir que, si un Estado traspasa la soberanía de otro con la transmisión de señales desde y hacia los satélites de posicionamiento global, este deberá asegurarse de ofrecer dicha información al Estado observado, al igual que deberá guardar la confidencialidad de la información de interés nacional que obtenga con dichos sistemas, en virtud del principio de cooperación internacional y la preservación de la soberanía de los Estados parte.

\section{Responsabilidad por la información que obtiene el satélite}

En este tema también existe regulación para los sistemas de teleobservación de la Tierra, más no existe información específica respecto de los sistemas de posicionamiento global. Por esta razón, y debido a las similitudes que existen con
Ios sistemas de teleobservación de la Tierra, se plantea que se use el mismo régimen que existe para la teleobservación de la Tierra. Así, se plantea que es obligación del Estado dueño de la información presentársela al Estado observado a un precio justo y razonable (Diago, 2014), al igual que, como se mencionaba anteriormente, deberá guardarse la información susceptible de vulnerar los intereses de algún otro Estado parte en lo que respecta a seguridad nacional.

\section{CONCLUSIONES}

El ser humano, desde el principio de los tiempos, tuvo siempre la necesidad de encontrar un método para ubicarse en el planeta desconocido e inhóspito que habitaba. Utilizó múltiples técnicas, como la estrella polar, la brújula y los mapas, pero nunca estuvo satisfecho con los resultados que obtenía. Solamente hasta que desarrollaron en el siglo XX los sistemas de navegación satelital, puede decirse que el hombre logró calmar sus ansias de no saber dónde estaba, de no saber qué había a su alrededor.

La apertura al mundo del posicionamiento global le entregó al hombre la libertad de los obstáculos que los sistemas tradicionales presentaban, pero abrió la puerta a nuevos obstáculos por la invasión de la soberanía de otros Estados, la fuerza vinculante de la norma de derecho espacial en el derecho y, en general, por el miedo y el riesgo de un eventual conflicto de proporciones espaciales. Frente a esto, el derecho espacial, sin duda, partiendo de la aplicación de los principios de cooperación internacional, no 
apropiación y uso pacífico, proporciona una respuesta a la mayoría de conflictos que puedan surgir, logrando establecerse como el "derecho de la paz".

Los sistemas de navegación satelital cambiaron radicalmente la forma de vida de los seres humanos, facilitándoles su transporte, su ubicación e inclusive sus vidas cotidianas. Al día de hoy, prácticamente ya todos los dispositivos cuentan con sistemas de posicionamiento global, por lo que en teoría es una tecnología global y está abierta. Considerando que los beneficios y los usos de este tipo de sistemas son infinitos, cabe preguntarse si deben fijarse en algún punto límites para su uso en cuanto al acceso a información privilegiada de algún otro Estado, el acceso a ubicaciones de posibles objetivos militares y las posibles interferencias que algún sistema le pueda generar a otro. Entonces, ¿cuál debe ser el límite entre los beneficios de los sistemas de navegación satelital y la soberanía de los Estados? ¿Debemos fijar límites al respecto?

Todo esto queda abierto al debate. Pero, a nuestra manera de ver las cosas, los principios del derecho espacial tienen suficiente fuerza vinculante y son suficientemente amplios para poder enfrentar los riesgos mencionados anteriormente y nuevos que puedan surgir.

\section{Referencias}

Bell, K. Ursa Minor. The Mythology of the Constellations. Recuperado de: http://www.comfychair.org/ cmbell/myth/ursa_minor.html
Botero, L. (2013). Régimen jurídico de los objetos espaciales.

Contreras, M. (2013). El espacio ultraterrestre. Una vez el origen, hoy el destino

Definición: longitud. Definición: longitud - latitud. Recuperado de: http://www.mathematicsdictionary.com/spanish/vmd/full/l/longitude. htm

Diago, M. P. (2014). Satélites de teleobservación de la Tierra. Aspectos técnicos y jurídicos.

Georgia State University (2008). Satélites de Posicionamiento Global. Recuperado de: http:// hyperphysics.phy-astr.gsu.edu/hbasees/gps. html

Gómez, S. (2013). Órbitas terrestres: clases, aspectos técnicos y jurídicos.

GPS in the Military Perspective. Recuperado de: http://www.ukessays.co.uk/essays/information-technology/gps-in-the-military-perspective.php

History of Navigation. Recuperado de: http:// infohost.nmt.edu/ mreece/gps/history.html

Introduction to Global Positioning System. Recuperado de: http://www.nhdfl.org/library/pdf/ Forest\%20Protection/Introduction\%20to\%20 Global\%20Positioning\%20System.pdf

Introduction to the Global Positioning System for GIS and TRAVERSE. Recuperado de: http:// www.cmtinc.com/gpsbook/ 
McDougal, M. S. (1963). The Emerging Customary Law of Space. Faculty Scholarship Series. Paper 2609. Recuperado de: http://digitalcommons.law.yale.edu/fss_papers/2609.

NASA. How Do Global Positioning Systems, or GPS, Work? Recuperado de: http://www. nasa.gov/audience/foreducators/topnav/ materials/listbytype/How_Do_Global_Positioning_Systems.html

-. Catalog of Earth Satellite Orbits. Recuperado de: http://earthobservatory.nasa.gov/Features/OrbitsCatalog/

Nelson, R. A. The Global Positioning System. Recuperado de: http://www.aticourses.com/ global_positioning_system.htm

Organización de Naciones Unidas, Oficina de Asuntos del Espacio Ultraterrestre (2008). Tratados y Principios de las Naciones Unidas sobre el Espacio Ultraterrestre. Nueva York: Estados Unidos.

Rey, J. R. An Introduction to GPS. Universidad de Florida. Recuperado de: http://edis.ifas.ufl. edu/pdffiles/IN/IN65300.pdf

Rincón, C. (2013). Aspectos jurídicos relativos a la utilización del espectro electromagnético y radioeléctrico y su importancia en las telecomunicaciones por satélite.

Rizos, C. (1999). Introduction to GPS - Chapter 1. Universidad de New South Wales. Recuperado de: http://www.gmat.unsw.edu.au/ snap/gps/gps_notes1.pdf
Robertson, M. The GPS Device. Recuperado de: http://www.lelandwest.com/car-accessoriesthe-gps-device.cfm

Sussmann, N. (2013). El Tratado de 1967: la extensión y garantía del mantenimiento de la paz y la seguridad internacional en el espacio.

Thirslund, S. (2007). Viking navigation. Roskilde, Dinamarca: Viking Ship Museum.

Varela Pérez, C. F. Sistemas de posicionamiento y de navegación satelital. Universidad El Bosque. Recuperado de: http://www.uelbosque. edu.co/sites/default/files/publicaciones/revistas/revista_tecnologia/volumen2_numero2/sistemas_posicionamiento2-2.pdf

What are GPS Systems used for? Recuperado de: http://www.sokkia.com.tw/NOVATEL/ gps/gps_systems.html

Williams, M. (2014). Dispute Settlement, Suborbital flights, use of satellite data and space debris, in Report of the Sixty-Sixth Conference of the International Law Association (ILA). Recuperado de: http://www.ila-hq.org

Williams, S. M. (1998). El riesgo ambiental y su regulación. Derecho internacional y comparado. Buenos Aires: Abeledo Perrot.

Yao, C. H. Global Positioning System (GPS) Technology and Car. Recuperado de: http://www. csa.com/discoveryguides/gpscars/overview. php 